University of Nebraska - Lincoln

DigitalCommons@University of Nebraska - Lincoln

Faculty Publications, Department of Psychology

Psychology, Department of

April 2004

\title{
The influence of personality and affect on nicotine dependence among male college students
}

Dennis E. McChargue

University of Nebraska-Lincoln, dmcchargue2@unl.edu

Lee M. Cohen

Texas Tech University of Lubbock

Jessica Warth Cook

M.A., University of Illinois at Chicago

Follow this and additional works at: https://digitalcommons.unl.edu/psychfacpub

Part of the Psychiatry and Psychology Commons

McChargue, Dennis E.; Cohen, Lee M.; and Warth Cook, Jessica, "The influence of personality and affect on nicotine dependence among male college students" (2004). Faculty Publications, Department of Psychology. 264.

https://digitalcommons.unl.edu/psychfacpub/264

This Article is brought to you for free and open access by the Psychology, Department of at DigitalCommons@University of Nebraska - Lincoln. It has been accepted for inclusion in Faculty Publications, Department of Psychology by an authorized administrator of DigitalCommons@University of Nebraska - Lincoln. 


\title{
The influence of personality and affect on nicotine dependence among male college students
}

\author{
Dennis E. McChargue, Lee M. Cohen, Jessica Werth Cook
}

[Received 30 September 2002; accepted 28 May 2003]

\begin{abstract}
Many clinicians and researchers hypothesize that tobacco use disorders, regardless of the route of administration, are maintained by the ability of nicotine to regulate positive and negative mood states. The present study $(N=137)$ examined whether certain mood states predicted dependence on either cigarettes or smokeless tobacco and whether specific personality characteristics (e.g., extraversion, neuroticism, and psychoticism) mediated these relationships among young male college students. Results indicated that positive and negative moods predicted cigarette dependence $(p$ values $=.01)$ and that neuroticism partially mediated the relationship between positive affect and cigarette dependence. Exploratory analyses revealed that positive affect also interacted with neuroticism to predict smokeless tobacco dependence $(p=.04)$. Simple effects analyses revealed that this relationship was maintained only among individuals high in neuroticism. Results suggested that dependence on cigarettes and smokeless tobacco among male college students may have different affective correlates and that certain personality characteristics may enhance and explain the effects of mood on tobacco dependence.
\end{abstract}

\section{Introduction}

Many people who regularly use tobacco products continue to have difficulty quitting even after intensive smoking treatment (Abrams, 1993; Hajeck, 1991; Hatsukami \& Severson, 1999; The Tobacco Use and Dependence Clinical Practice Guideline Panel, Staff, and Consortium Representatives, 2000). It has been suggested that individuals who become dependent on tobacco products vary across several biobehavioral factors that impede the maintenance of nicotine abstinence (Shiffman, 1991). The identification and assessment of such individual difference factors may help in the development of more efficacious treatment options in the future (Shiffman, 1993; The Tobacco Use and Dependence Clinical Practice Guideline Panel, Staff, and Consortium Representatives, 2000).

Dennis E. McChargue, Ph.D., University of Illinois at Chicago and the Edward Hines, Jr., VA Hospital; Lee M.Cohen, Ph.D., Texas Tech University of Lubbock; and Jessica Werth Cook, M.A., University of Illinois at Chicago.

Correspondence: Dennis E McChargue, Ph.D., Department of Psychology (M/C 285), University of Illinois at Chicago, $1007 \mathrm{~W}$. Harrison Street, Chicago, IL 60607, USA. Tel: + 1 (312)-355-2141; Fax: +1 (312)-355-2155; E-mail: dmccharg@uic.edu
Compulsive tobacco use has been conceptualized as an addictive process reinforced by repeated exposure to nicotine (Jaffe, 1990; West, 1988). Although other explanations of reinforcement have been put forth (Landrine, Richardson, Klonoff, \& Flay, 1994), tobacco use is believed to be maintained because nicotine modulates various neurotransmitter systems (e.g., dopamine, serotonin, acetylcholine, glutamate) associated with the production of desirable positive mood states (Pomerleau \& Pomerleau, 1992; Watkins, Koob, \& Markou, 2000) or the alleviation of undesirable negative mood states (Carmody, 1992; Hall, Munoz, Reus, \& Sees, 1993).

To date, the influence of mood on tobacco use disorders has been studied primarily among individuals who smoke cigarettes. Less is known about individuals who use smokeless tobacco. Nevertheless, many researchers assume that the contribution of affect on the maintenance of tobacco use behavior is the same for smokeless tobacco users as it is for cigarette smokers. For example, studies that examine the motives of cigarette smokers and smokeless tobacco users report that the management of emotions is one of the most important reasons for continued use of tobacco for both groups (Spielberger, Foreyt, Reheiser, \& Poston, 1998). Situations that evoke negative moods also have been shown to be strongly 
associated with cigarette smoking (Spielberger \& Jacobs, 1982) and smokeless tobacco use (Hatsukami \& Severson, 1999).

Other studies have suggested that biological and psychological predispositions, such as personality traits, may help explain the influence of mood on tobacco use disorders (Gilbert \& Gilbert, 1995; Lerman et al., 1998; Pomerleau, 1995; Robinson \& Berridge, 2000). For decades, many personality theories have emphasized how traits influence affective experiences throughout one's lifespan (Ekman, 1984; Izard, 1977; Malatesta \& Wilson, 1988; Plutchik, 1980; Tellegen, 1985; Tomkins \& McCarter, 1964). Although research has yet to identify which personality characteristic best predicts tobacco use, studies have shown that neuroticism, extraversion, and psychoticism each exert some influence on tobacco use (Canals, Blade, \& Domenech, 1997; Eysenck, Tarrant, Woolf, \& England, 1960; Gilbert \& Gilbert, 1995; Pritchard \& Kay, 1993; Spielberger \& Jacobs, 1982). For example, studies have shown that, among cigarette smokers, neuroticism was an important predictor of craving following the pharmacological manipulation of the dopamine system (Reuter \& Netter, 2001). Moreover, smokeless tobacco users, particularly those who reported occasional use, had higher scores in extraversion (Spielberger, Foreyt, Goodrick, \& Reheiser, 1995; Spielberger, Reiheiser, Carlos, \& Foreyt, 2000). When smokeless tobacco users were compared with cigarette smokers, both groups were shown to be high in psychoticism, whereas cigarette smokers also were high in neuroticism and suppressed anger and low in trait curiosity (Spielberger et al., 1995). Whether personality characteristics explain the influence of mood on tobacco use and dependence remains unclear.

Based on the findings from prior research suggesting that mood states predict cigarette smoking (Spielberger et al., 1998) and smokeless tobacco use (Foreyt et al., 1997), the present study tested the hypothesis that negative and positive moods predict nicotine dependence among tobacco-using undergraduates. The present study also examined whether personality mediates the relationship between affect and nicotine dependence. Although the personality variables that may explain the relationship between mood and dependence are unclear, findings from prior research may lead one to expect neuroticism to act as a mediator among the analyses examining dependence on cigarettes and extraversion to exert mediation effects among the analyses examining dependence on smokeless tobacco.

\section{Method}

\section{Participants}

A total of 137 male undergraduate psychology students, all of whom reported using one or more tobacco products, participated in the present study to fulfill course requirements (Table 1). Given estimates indicating that males aged 12 years or older are 10 times more likely than their female counterparts to report current use of smokeless tobacco (i.e., $6.5 \%$ of males vs. $.5 \%$ of females) (Substance Abuse and Mental Health Services Administration, 2001), the participant sample was restricted to male volunteers. On average, participants were 19 years old (median = 19 years). The sample was $88.4 \%$ White, $6.5 \%$ Hispanic, . $7 \%$ Black, . $7 \%$ Native American, and 3\% "Other." Of the 137 participants, 83 reported smoking only cigarettes, 24 reported using only smokeless tobacco, and 30 reported use of both cigarettes and smokeless tobacco. The dual users were included in both the cigarette and the smokeless tobacco dependence analyses. On average, the participants reported smoking more than 4 days per week $(M=4.75$, $S D=2.57$ ). During each day that participants reported smoking cigarettes, $59.2 \%$ reported smoking 5 or fewer cigarettes, $14.8 \%$ reported smoking 6-10 cigarettes, $12.8 \%$ reported smoking $11-20$ cigarettes, and $13.2 \%$ reported smoking 20 or more. Those who used only smokeless tobacco reported chewing approximately 6 days per week $(M=5.91, S D=1.44)$, and dual users reported chewing close to 4 days each week $(M=3.67, \quad S D=2.56)$. Finally, smokeless tobacco users reported using an average of 2.87 tins per week $(S D=1.57)$, and dual users reported using an average of 2.21 tins per week $(S D=2.56)$.

\section{Measures}

Cigarette dependence. Cigarette dependence was assessed using the Fagerström Test for Nicotine Dependence (FTND; Heatherton, Kozlowski, Frecker, \& Fagerström, 1991). The FTND measures symptoms of nicotine dependence on a six-item scale. Potential scores on the FTND range from 0 to 10; higher scores indicate greater dependence. The FTND exhibits moderate internal consistency (Cronbach's

Table 1. Demographic and nicotine use characteristics $(N=137)$.

\begin{tabular}{lrrr}
\hline Variable & Mean & $S D$ & Range \\
\hline FTND score & 2.76 & 2.61 & $0-10$ \\
MFST score & 1.31 & 1.54 & $0-6$ \\
Extraversion & 12.69 & 2.72 & $6-30$ \\
Neuroticism & 10.42 & 5.21 & $1-40$ \\
Psychoticism & 5.47 & 1.54 & $2-14$ \\
Negative affect & 15.14 & 5.85 & $10-40$ \\
Positive affect & 26.84 & 8.46 & $10-50$ \\
Negative affect & 23.10 & 22.22 & $0-113$ \\
Vigor & 15.04 & 6.29 & $1-32$ \\
\hline
\end{tabular}

FTND, Fagerström Test for Nicotine Dependence; MFST, Modified FTND for Smokeless Tobacco Users. 
$\alpha=.64$ and .58 , respectively) and construct validity (Pomerleau, Carton, Lutzke, Flessland, \& Pomerleau, 1994).

Smokeless tobacco dependence. Smokeless tobacco dependence was measured via a Modified FTND for Smokeless Tobacco Users (MFST; Boyle, Jensen, Hatsukami, \& Severson, 1995). The MFST examines five items that assess patterns of smokeless tobacco use, ability to refrain from smokeless tobacco, and the rate of smokeless tobacco use. Potential scores on the MFST range from 0 to 10 with higher scores reflecting greater smokeless tobacco dependence. Although reported coefficient alphas for the MFST are relatively low (e.g., .55, .51) (Boyle et al., 1995), such results are sometimes found among nicotine dependence scales (Lichtenstein \& Mermelstein, 1986).

Positive affect. Positive affect was assessed throughout the study via two subjective measures of mood: The vigor subscale of the Profile of Mood States (POMS) questionnaire (McNair, Lorr, \& Droppleman, 1971) and the positive affect subscale of the Positive and Negative Affect Scale (PANAS; Watson, Clark, $\&$ Tellegen, 1988). Although the POMS and PANAS are highly intercorrelated, the POMS vigor subscale and the PANAS positive affect subscale measure different components of positive affect. Specifically, the vigor subscale measures activated positive mood states (e.g., full of pep, vigorous, energetic, active), whereas the positive affect subscale includes many descriptors that tap into low-activation positive mood states (e.g., proud, strong, determined, interested). As suggested by Watson and Tellegen (1985), highactivation positive mood states and low-activation positive mood states are different types of emotions that have different psychological and behavioral correlates. Both measures were included because little is known about the how positive affect influences nicotine dependence.

The POMS is a self-report mood questionnaire consisting of 65 adjectives rated on a five-point Likert scale ranging from 0 (not at all) to 4 (extremely) (McNair et al., 1971). The "right now" version was used to characterize the participant's mood at the time of testing. The POMS vigor subscale assessed highactivation positive mood states, by measuring moods such as peppiness, elation, and vigor. Potential scores for this subscale range from 0 to 32; higher scores indicate higher levels of vigor. The vigor-activity subscale has an internal consistency reliability of .90 and shows evidence of both construct and predictive validity (McNair et al., 1971).

Positive affect also was measured via the PANAS, given that it measures lower activation positive mood states (e.g., strong, proud, interested). Study participants rated the extent to which each word described the way they felt at the moment of testing on a five-point Likert scale $(1=$ very slightly or not at all, $5=$ extremely). The positive affect scale consists of 10 items, with potential scores ranging from 10 to 50 . Higher scores on the positive affect scale indicate higher levels of positive affect. The positive affect scale had high internal consistency $(\alpha=.87)$ among a sample of adults (Watson et al., 1988).

Negative affect. Negative affect was assessed throughout the study via two subjective measures of mood: The negative affect subscale of the POMS (McNair et al., 1971) and the negative affect subscale of the PANAS (Watson et al., 1988). The "right now" version of the POMS was used to characterize the participant's mood at the time of testing. Negative affect, encompassing feelings of distress, hostility, nervousness, scorn, and gloominess (Watson \& Tellegen, 1985), was measured by the POMS negative affect subscale, derived by summing the subscale scores for tension, depression, and anger. Potential negative affect scores range from 0 and 144; higher scores indicate higher levels of negative affect. The negative subscale has an internal consistency reliability of .90 and evidences construct and predictive validity (McNair et al., 1971).

The negative affect subscale of the PANAS was used to derive a measure of negative affect. The negative affect scale comprises 10 words, with scores ranging from 10 to 50 . Higher scores indicate higher levels of negative affect. The negative affect scale had high internal consistency $(\alpha=.84)$ in a sample of adults (Watson et al., 1988).

Personality. Extraversion, neuroticism, and psychoticism were measured using the Eysenck Personality Questionnaire (EPQ; Eysenck \& Eysenck, 1975). The EPQ contains 90 true-false items and yields scores on the three dimensions of Eysenck's personality theory: Extraversion, neuroticism, and psychoticism. The EPQ shows satisfactory split-half reliability (Eysenck \& Eysenck, 1975).

Stage of change. Dependence and withdrawal may differ among individuals across levels of motivation to quit (Prokhorov et al., 2001). As a result, the contemplation ladder (Biener \& Abrams, 1991) was administered to assess nicotine users' position on a continuum ranging from having no thoughts of quitting to being engaged in action to change one's smoking behavior. The five stages of readiness on the contemplation ladder, which correspond with the stages of change model (Prochaska, DiClemente, \& Norcross 1992) are as follows: "No thought of quitting," "Think I need to consider quitting someday," 
"Thinking I should quit but not quite ready," "Starting to think about how to change my tobacco use patterns," and "Taking action to quit" (e.g., cutting down, enrolling in a program). The contemplation ladder has both concurrent and predictive validity (Biener \& Abrams, 1991).

Social desirability. Social desirability was assessed to control for demand characteristics produced by the study's quasi-experimental design (i.e., using selfreport only) (Wilkerson, Nagao, \& Martin, 2002). The social desirability measure used in the present study originates from the social acceptance vs. social intolerance subscale of the Temperament and Character Inventory (TCI; Cloninger, Pryzbeck, Svrakic, \& Wetzel, 1994). The internal consistencies of the TCI subscales have been shown to be high (Cloninger et al., 1994).

\section{Procedures}

Informed consent was obtained independently from all participants prior to their entry into the study. Potential participants signed up for 2-hr assessment sessions held twice weekly in groups of 15 to 20 ; each participant was awarded course credit for his participation. Assessment sessions occurred between 11.00 and $16.00 \mathrm{hr}$. To reduce order effects, questionnaire packets were counterbalanced in terms of the order in which each measure appeared in the packet. No identifiable information appeared on the questionnaire packets.

\section{Results}

Hierarchical regression analyses were conducted to examine the study hypotheses. First, Pearson correlations were conducted to examine correlations among study variables (Table 2). Correlation analyses showed that stage of readiness to quit using tobacco was significantly correlated with FTND and negative affect, whereas social desirability was significantly associated with negative affect. Thus, both stage of readiness to quit using tobacco and social desirability were statistically controlled in all analyses.

\section{Positive mood and nicotine dependence (MFST and FTND)}

The first hypothesis was that current positive mood states would predict smokeless tobacco and cigarette dependence. Hierarchical regression analysis showed that the positive affect (PANAS) subscale predicted $6 \%$ of the variance in cigarette dependence, after we controlled for stage of change and social desirability, $R^{2}$ change $=.06, \beta=-.24, F(1,100)=7.13, p=.01$. Variance in smokeless tobacco dependence, however, was not predicted by the positive affect subscale, $F(1,49)=1.11, p=.30$. Likewise, vigor (POMS) did not predict significant variance in FTND scores, $F(1,99)=2.97, p=.09$, or MFST scores, $F(1,47)=.16$, $p=.69$, after we controlled for covariates.

\section{Negative mood and nicotine dependence (MFST and FTND)}

The second hypothesis was that current negative mood states would predict dependence on smokeless tobacco and cigarettes. Hierarchical regression analysis showed that negative affect (POMS) accounted for $7 \%$ of the variance in cigarette dependence, after we controlled for social desirability and stage of change, $R^{2}$ change $=.07, \beta=.26, F(1,99)=8.48, p=.01$. A subsequent hierarchical regression analysis showed that POMS negative affect did not predict dependence on smokeless tobacco, $F(1,49)=.09, p=.76$. Likewise, the negative affect subscale (PANAS) did not predict significant variance in FTND scores, $F(1,100)=1.79$, $p=.18$, or MFST scores, $F(1,49)=2.80, p=.60$, after we controlled for covariates.

Table 2. Intercorrelations among baseline predictor variables and criterion variables $(N=137)$.

\begin{tabular}{|c|c|c|c|c|c|c|c|c|c|c|c|c|}
\hline & 1 & 2 & 3 & 4 & 5 & 6 & 7 & 8 & 9 & 10 & 11 & 12 \\
\hline FTND & - & & & & & & & & & & & \\
\hline MFST & .20 & - & & & & & & & & & & \\
\hline Positive affect & $-.26^{\star}$ & - & & & & & & & & & & \\
\hline Negative affect & .09 & .05 & -.14 & - & & & & & & & & \\
\hline Vigor & $-.21^{\star}$ & .02 & $.57^{\star \star}$ & $-.20^{\star}$ & - & & & & & & & \\
\hline Dysphoria & $.26^{*}$ & .04 & $-.27^{\star \star}$ & $.69^{\star \star}$ & $-.36^{\star \star}$ & - & & & & & & \\
\hline Neuroticism & $.25^{\star \star}$ & .04 & $-.23^{\star \star}$ & $.42^{\star *}$ & $-.32^{\star \star}$ & $.51^{\star \star}$ & .09 & - & & & & \\
\hline Psychoticism & -.02 & -.04 & .11 & .10 & .01 & .06 & .14 & $.34^{\star \star}$ & - & & & \\
\hline Stage of change (smoking) & $-.32^{*}$ & $.44^{\star \star}$ & .03 & .05 & .06 & -.01 & -.12 & -.01 & -.05 & - & & \\
\hline Stage of change (smokeless) & - & -.22 & -.07 & $-.23^{\star}$ & -.04 & -.17 & -.13 & -.18 & -.17 & $.40^{\star}$ & - & \\
\hline Social desirability & .10 & -.10 & -.01 & $.16^{\star}$ & -.08 & .09 & $.24^{\star \star}$ & .01 & .02 & $-.18^{\star}$ & $-.31^{\star}$ & \\
\hline
\end{tabular}

FTND, Fagerström Test for Nicotine Dependence; MFST, Modified FTND for Smokeless Tobacco Users.

${ }^{* *} p<.01,{ }^{*} p<.05$, one-tailed. 
Overall, positive affect and negative affect predicted significant changes in dependence on cigarettes, after we controlled for covariates. Next, we examined whether personality variables would mediate the effects of positive affect and negative affect on cigarette dependence. Given that only neuroticism was significantly correlated with positive affect, negative affect, and FTND scores and that extraversion and psychoticism did not show the significant zero-order correlations to warrant viability as a potential mediator (Table 2), the first set of analyses tested whether neuroticism mediated the influence of positive affect and negative affect on cigarette dependence.

\section{Positive affect and cigarette dependence: Partial mediation by neuroticism}

Hierarchical regression analysis tested whether neuroticism mediated the relationship between positive moods and dependence on cigarettes. Using criteria set by Baron and Kenny (1986), we examined whether (a) positive affect predicted FTND, (b) positive affect predicted the mediator (neuroticism), and (c) only neuroticism significantly predicted dependence on cigarettes, when neuroticism and positive affect were placed on the same regression step. As shown above, positive affect predicted significant variance in dependence on cigarettes. Next, hierarchical regression analysis, after we controlled for covariates, showed that positive affect significantly predicted neuroticism, $R^{2}$ change $=.06, \beta=-.24, F(1,100)=6.32, p=.01$. When neuroticism and positive affect were entered into the same step of the regression equation, after we controlled for covariates, both positive affect, $\beta=-.18, p=.04$, and neuroticism, $\beta=.19, p=.03$, predicted significant additional variance in FTND scores. Results suggested that neuroticism partially mediated the relationship between positive affect and level of dependence on cigarettes (Baron \& Kenny, 1986). Although the influence of positive affect on cigarette dependence remained significant, the observed reduction in beta weight and alpha value suggested partial mediation (Baron \& Kenny, 1986).

\section{Negative affect and cigarette dependence: Lack of mediation by neuroticism}

Hierarchical regression analysis also tested whether neuroticism mediated the relationship between negative affect and dependence on cigarettes. As shown above, negative affect predicted significant variance in dependence on cigarettes. Next, hierarchical regression analysis, after we controlled for covariates, showed that negative affect significantly predicted neuroticism, $R^{2}$ change $=.29, \quad \beta=.54, \quad F(1,98)=39.86, \quad p=.01$. When neuroticism and negative affect were entered into the same step of the regression equation after controlling for covariates, neither predicted significant additional variance in FTND scores $(p$ values $=.25$ and .08 , respectively). Results suggested that neuroticism did not mediate the relationship between negative affect and dependence on cigarettes (Baron \& Kenny, 1986).

\section{Exploratory analysis: Neuroticism moderates the influence of positive moods on smokeless tobacco dependence}

The partial mediation of positive affect and cigarette smoking by neuroticism illustrated the influence of neuroticism on nicotine dependence via a positive affect pathway. Because moderation effects are most desirable when an unexpectedly weak relationship exists between predictor and criterion variables (Baron $\&$ Kenny, 1986), we conducted an exploratory analysis that tested whether neuroticism would moderate positive affect to influence smokeless tobacco dependence. Again, using the criteria established by Baron and Kenny (1986), we first examined whether the moderator variable (positive affect $\times$ neuroticism) predicted significant variance in smokeless dependence after controlling for the main effects of positive affect and neuroticism. Specifically, hierarchical regression analysis showed that, after we controlled for covariates, current positive moods, and neuroticism, the moderator variable (positive affect $\times$ neuroticism) explained $7 \%$ of the variance in smokeless dependence, $R^{2}$ change $=.07, F(1,47)=4.17, p=.04$. Simple effects were conducted with two separate regression analyses that examined the relationship between positive affect and smokeless tobacco dependence first among individuals with high levels of neuroticism only and then among individuals with low levels of neuroticism. Results showed that current positive mood was predictive of smokeless dependence among those with high levels of neuroticism, $R^{2}$ change $=.14, F(1$, $25)=4.29, p=.04$, but not among those with low levels of neuroticism, $F(1,20)=.48, p=.50$. Thus, neuroticism appeared to interact with positive mood states such that only among those with high neuroticism did positive affect predict dependence on smokeless tobacco.

\section{Discussion}

Our findings illustrated the importance of testing individual difference factors when examining the nature of the relationship between affect and nicotine dependence among a young college student population that reported varying tobacco use histories. After controlling for stage of change and social desirability, we found that lower levels of positive affect and higher levels of negative affect predicted dependence 
on cigarettes but not on smokeless tobacco. The results from this study provide evidence that neuroticism partially mediated the negative relationship between positive affect and cigarette dependence. Exploratory analyses also found that neuroticism moderated the influence of positive affect on smokeless tobacco dependence. Specifically, simple effects tests revealed a significant negative relationship between positive affect and smokeless tobacco dependence among highly neurotic individuals and not among individuals with low levels of neuroticism.

To our knowledge, the present study may be the first to examine the influence of personality on the relationship between affect and different types of nicotine dependence. By doing so, we have attempted to characterize biobehavioral factors associated with cigarette dependence and smokeless tobacco dependence. Our results indicated that positive affect and dysphoria predicted cigarette dependence among male undergraduates. In fact, young smokers without extensive histories of cigarette smoking may very well continue to smoke because nicotine elevates their positive moods (Lipkus, Barefoot, Williams, \& Siegler, 1994) and reduces feelings of negative affect (Breslau, 1995; Escobedo, Kirch, \& Anda, 1996; Gilbert \& Wesler, 1989). Interestingly, neuroticism explained the influence of positive affect, but not negative affect, on cigarette dependence. Historically, neurotic smokers were presumed to become dependent on nicotine because of its ability to ameliorate their frequent and persistence bouts of unpleasant moods (Gilbert \& Gilbert, 1995). Our results, however, suggested that this vulnerability may drive male smokers toward behaviors that evoke or ameliorate presumed deficits in positive affect.

With respect to individuals who use smokeless tobacco, low levels of positive affect also appear to influence smokeless tobacco dependence among individuals with high levels of neuroticism. Consistent with previous research (Spielberger et al., 1998), smokeless tobacco users may become dependent on nicotine because they achieve some level of enjoyment or pleasure from its use. The present study provided preliminary data suggesting that smokeless tobacco users chew for enjoyment purposes. In fact, young male neurotic smokeless tobacco users may chew tobacco because they have difficulty experiencing enjoyment or pleasure during situations that are naturally rewarding to others. In other words, smokeless tobacco may ameliorate such deficits in pleasure.

Given that neuroticism heightens negative mood states during short-term abstinence (Breslau, Kilbey, \& Andreski, 1992; Gilbert et al., 1998; Gilbert et al., 2002), but typically does not have an effect on positive mood states measured by POMS vigor scores (Gilbert et al., 1998), one might expect that temporary abstinence effects could influence the present findings during the 2-hr testing period. Contrary to this supposition, however, low levels of positive affect rather than elevated negative affect influenced the relationship between neuroticism and nicotine dependence. Hence, our findings were more consistent with prequit correlates that showed neuroticism positively correlated with depression and tension and negatively correlated with vigor (Gilbert et al., 1998). These data suggested that participants in the present study may not have experienced substantial symptoms of nicotine withdrawal that would have influenced the results.

An overall speculative interpretation of our data is that the effect of neuroticism on the negative relationship between positive affect and nicotine dependence among male cigarette smokers and smokeless tobacco users may support a depressive vulnerability hypothesis of nicotine dependence. Although it is unclear whether nicotine use increases an individual's risk of experiencing depression (Balfour \& Ridley, 2000) or whether it is a reaction to a depressive vulnerability (Glassman et al., 1988), data from this study appear to support the idea that young neurotic males who experience deficits in positive affect may use nicotine to buffer their risk of depression or to ameliorate neurobiological substrates that may predispose them to depression. This possibility is consistent with the view that neuroticism is a precursor to depression (Jorm et al., 2000). Additionally, a deficiency in positive affect by itself or in combination with elevated negative affect is viewed as the key ingredient to clinically significant depression (Clark \& Watson, 1991; Coyne, 1994). As such, it may be reasonable to assume that the combination of neuroticism and low positive affect reflect a proxy for a depressive vulnerability among young tobaccousing males. Nevertheless, the depressive vulnerability hypothesis is tenuous at best and should be evaluated more rigorously in future studies.

Despite the encouraging results, the present study had a number of limitations. For example, results were based on a small sample of male college students. Thus, the extent to which these findings can be generalized to female or older individuals who have used tobacco products for a longer period of time has not been determined. The relatively low dependence levels observed between cigarette and smokeless tobacco users also limits generalizability to populations showing higher levels of nicotine dependence. Given the nature of the results (e.g., correlational), we cannot infer causality. That is, an individual with specific personality characteristics or with a propensity to experience low positive or elevated negative affect will not necessarily become dependent on a product containing tobacco. In addition, questionnaires were disseminated between 11.00 and $16.00 \mathrm{hr}$. Time of day may have interacted with the influence of personality variables on mood and dependence. Also, mood measures were momentary and situation specific 
(measured at one time point). Given that mood is influenced by a variety of environmental stimuli, it is unclear whether these relationships would be witnessed in other situations.

In conclusion, results from the present study indicated that a distinct relationship exists between affective states and nicotine dependence among male college students. Furthermore, neuroticism was shown to exert some influence on these relationships. However, because data were collected at one time point and participants consisted of individuals with varying patterns of tobacco use, our results are preliminary at best. Future research should examine these hypotheses longitudinally and among individuals with homogeneous tobacco use patterns.

\section{Acknowledgments}

This research was supported by grants K08DA00467 to Dennis McChargue and DA14144 to Jessica Werth.

\section{References}

Abrams, D. B. (1993). Treatment issues: Towards a stepped-care model. Tobacco Control, 2(Suppl.), S17-S37.

Balfour, D. J. K., \& Ridley, D. L. (2000). The effects of nicotine on neural pathways implicated in depression: A risk factor in nicotine dependence?. Pharmacology, Biochemistry, and Behavior, 66, 79-85.

Baron, R. M., \& Kenny, D. A. (1986). The moderator-mediator variable distinction in social psychological research: Conceptual, strategic, and statistical considerations. Journal of Personality and Social Psychology, 51, 1173-1182.

Biener, L., \& Abrams, D. B. (1991). The contemplation ladder: Validation of a measure of readiness to consider smoking cessation. Health Psychology, 10, 360-365.

Boyle, R. G., Jensen, J., Hatsukami, D. K., \& Severson, H. H. (1995). Measuring dependence in smokeless tobacco users. Addictive Behaviors, 20, 443-450.

Breslau, N. (1995). Psychiatric comorbidity of smoking and nicotine dependence. Behavior Genetics, 25, 95-101.

Breslau, N., Kilbey, M. M., \& Andreski, P. (1992). Nicotine withdrawal symptoms and psychiatric disorders: Findings from an epidemiologic study of young adults. American Journal of Psychiatry, 149, 464-469.

Canals, J., Blade, J., \& Domenech, E. (1997). Smoking and personality predictors in young Spanish people. Personality and Individual Differences, 23, 905-908.

Carmody, T. P. (1992). Affect regulation, nicotine addiction, and smoking cessation. Journal of Psychoactive Drugs, 24, 111-122.

Clark, L. A., \& Watson, D. (1991). Tripartite model of anxiety and depression: Psychometric evidence and taxonomic implications. Journal of Abnormal Psychology, 100, 316-336.

Cloninger, C. R., Pryzbeck, T. R., Svrakic, D. M., \& Wetzel, R. D. (1994). The Temperament and Character Inventory (TCI): A guide to its development and use. St. Louis, MO: Center for Psychobiology of Personality, Washington University.

Coyne, J. C. (1994). Self-reported distress. Psychological Bulletin, 116, $29-46$.

Ekman, P. (1984). Expression and the nature of emotion. In K. Scherer \& P. Ekman (Eds.), Approaches to emotion (pp.329-343). Hillsdale, NJ: Erlbaum Associates.

Escobedo, L. G., Kirch, D. G., \& Anda, R. F. (1996). Depression and smoking initiation among U.S. Latinos. Addiction, 91, 113-119.

Eysenck, H. J., \& Eysenck, S. B. G. (1975). Manual of the Eysenck Personality Questionnaire. San Diego, CA: Educational and Industrial Testing Service.

Eysenck, H. J., Tarrant, M., Woolf, M., \& England, L. (1960). Smoking and personality. British Medical Journal, 5184, 1456-1460.

Foreyt, J. P., Goodrick, G. K., Schaefer, C., Jackson, A. S., Squires,
W. G., \& Poston, W. S. C., II. (1997). Personality characteristics of current and former smokeless tobacco users. American Journal of Health Behavior, 21, 299-309.

Gilbert, D. G., \& Gilbert, B. O. (1995). Personality, psychopathology, and nicotine response as mediators of the genetics of smoking. Behavior Genetics, 25, 133-147.

Gilbert, D. G., McClernon, F. J., Rabinovich, N. E., Plath, L. C., Jensen, R. A., \& Meliska, C. J. (1998). Effects of smoking abstinence on mood and craving in men: Influences of negativeaffect-related personality traits, habitual nicotine intake and repeated measurements. Personality and Individual Differences, 25 , 399-423.

Gilbert, D. G., McClernon, F. J., Rabinovich, N. E., Plath, L. C., Masson, C. L., Anderson, A. E., \& Sly, K. F. (2002). Mood disturbance fails to resolve across 31 days of cigarette abstinence in women. Journal of Consulting and Clinical Psychology, 70, 142-152.

Gilbert, D. G., \& Wesler, R. (1989). Emotion, anxiety and smoking. In T. Ney \& A. Gale (Eds.), Smoking and human behavior (pp. 171-196). New York: Wiley.

Glassman, A. H., Stetner, F., Walsh, T., Raizman, P. S., Fleiss, J. L., Cooper, T. B., \& Covey, L. S. (1988). Heavy smokers, smoking cessation, and clonidine: Results of a double-blind, randomized trial. The Journal of the American Medical Association, 259, 2863-2866.

Hajeck, P. (1991). Individual differences in difficulty quitting smoking. British Journal of Addiction, 86, 555-558.

Hall, S. M., Munoz, R. F., Reus, V. I., \& Sees, K. L. (1993). Nicotine, negative affect, and depression. Journal of Consulting and Clinical Psychology, 61, 761-767.

Hatsukami, D. K., \& Severson, H. H. (1999). Oral spit tobacco: Addiction, prevention, and treatment. Nicotine \& Tobacco Research, 1, 21-44.

Heatherton, T. F., Kozlowski, L. T., Frecker, R. C., \& Fagerström, K.-O. (1991). The Fagerström Test for Nicotine Dependence: A revision of the Fagerström Tolerance Questionnaire. British Journal of Addiction, 86, 1119-1127.

Izard, C. (1977). Human emotions. New York: Plenum.

Jaffe, J. H. (1990). Tobacco smoking and nicotine dependence. In S. Wonnacott, M. A. H. Russell, \& I. P. Stolerman (Eds.), Nicotine psychopharmacology: Molecular, cellular, and behavioral aspects (pp. 1-37). Oxford, England: Oxford University Press.

Jorm, A. F., Christenen, H., Henderson, A. C., Jacomb, P. A., Korten, A. E., \& Rodgers, B. (2000). Predicting anxiety and depression from personality: Is there a synergistic effect of neuroticism and extraversion?. Journal of Abnormal Psychology, 109, 145-149.

Landrine, H., Richardson, J. L., Klonoff, E. A., \& Flay, B. R. (1994). Cultural diversity in the predictors of adolescent cigarette smoking: The relative influence of peers. Journal of Behavioral Medicine, 17, $331-346$.

Lerman, C., Caporaso, N., Main, D., Audrain, J., Boyd, N. R., Bowman, E. D., \& Shields, P. G. (1998). Depression and selfmedication with nicotine: The modifying influence of the dopamine receptor gene. Health Psychology, 17, 56-62.

Lichtenstein, E., \& Mermelstein, R. J. (1986). Some methodological cautions in the use of the Tolerance Questionnaire. Addictive Behaviors, 11, 439-442.

Lipkus, I. M., Barefoot, J. C., Williams, R. B., \& Siegler, I. C. (1994). Personality measures as predictors of smoking initiation and cessation in the UNC Alumni Heart Study. Health Psychology, 13, 149-155.

Malatesta, C. Z., \& Wilson, A. (1988). Emotion/cognition interaction in personality development: A discrete emotions, functionalist analysis. British Journal of Social Psychology, 27, 91-112.

McNair, D. M., Lorr, M., \& Droppleman, L. F. (1971). Profile of Mood States manual. San Diego, CA: Educational and Industrial Testing Service.

Plutchik, R. (1980). Emotions: A psychoevolutionary perspective. New York: Harper \& Row.

Pomerleau, C. S., Carton, S. M., Lutzke, M. L., Flessland, K. A., \& Pomerleau, O. F. (1994). Reliability of the Fagerström Tolerance Questionnaire and the Fagerström Test for Nicotine Dependence. Addictive Behaviors, 19, 33-39.

Pomerleau, C. S., \& Pomerleau, O. F. (1992). Euphoriant effects of nicotine in smokers. Psychopharmacology, 108, 460-465.

Pomerleau, O. F. (1995). Individual differences in sensitivity to nicotine: Implications for genetic research on nicotine dependence. Behavior Genetics, 25, 161-175. 
Pritchard, W. S., \& Kay, D. L. C. (1993). Personality and smoking motivation of U.S. smokers as measured by the State-Trait Personality Inventory, the Eysenck Personality Questionnaire and Speilberger's Smoking Motivation Questionnaire. Personality and Individual Differences, 14, 629-637.

Prochaska, J. O., DiClemente, C. C., \& Norcross, J. C. (1992). In search of how people change - Applications to addictive behaviors. American Psychologist, 47, 1102-1114.

Prokhorov, A. V., Hudmon, K. S., de Moor, C. A., Kelder, S. H., Conroy, J. L., \& Ordway, N. (2001). Nicotine dependence, withdrawal symptoms, and adolescents' readiness to quit smoking. Nicotine \& Tobacco Research, 3, 151-155.

Reuter, M., \& Netter, P. (2001). The influence of personality on nicotine craving: A hierarchical multivariate statistical prediction model. Neuropsychobiology, 44, 47-53.

Robinson, T. E., \& Berridge, K. C. (2000). The psychology and neurobiology of addiction: An incentive-sensitization view. Addiction, 95(Suppl. 2), S91-S117.

Shiffman, S. (1991). Refining models of dependence: Variations across persons and situations. British Journal of Addiction, 86, 611-615.

Shiffman, S. (1993). Assessing smoking patterns and motives. Journal of Consulting and Clinical Psychology, 61, 732-742.

Spielberger, C. D., Foreyt, J. P., Goodrick, G. K., \& Reheiser, E. C. (1995). Personality characteristics of users of smokeless tobacco compared with cigarette smokers and non-users of tobacco products. Personality and Individual Differences, 19(4), R.

Spielberger, C. D., Foreyt, J. P., Reheiser, E. C., \& Poston, W. S. C. (1998). Motivational, emotional, and personality characteristics of smokeless tobacco users compared with cigarette smokers. Personality and Individual Differences, 25, 821-832.

Spielberger, C. D., \& Jacobs, G. A. (1982). Personality and smoking behavior. Journal of Personality Assessment, 46, 396-403.

Spielberger, C. D., Reheiser, E. C., Carlos, P. W., \& Foreyt, J. P. (2000). Personality, motivation and situational determinants of regular and occasional use of smokeless tobacco. Personality and Individual Differences, 28, 1159-1170.

Substance Abuse and Mental Health Services Administration. (2001). Summary of findings from the 2000 National Household Survey on Drug Abuse (DHHS Publication No. SMA 01-3549, Chapter 4). Rockville, MD: U.S. Department of Health and Human Services.

Tellegen, A. (1985). Structures of mood and personality and their relevance to assessing anxiety, with an emphasis on self-report. In H. Tuma \& J. Maser (Eds.), Anxiety and anxiety disorders (pp. 681-706). Hillsdale, NJ: Erlbaum Associates.

The Tobacco Use and Dependence Clinical Practice Guideline Panel, Staff, and Consortium Representatives. (2000). A clinical practice guideline for treating tobacco use and dependence: A U.S. Public Health Service report. The Journal of the American Medical Association, 283(24), 3244-3254.

Tomkins, S., \& McCarter, R. (1964). What and where are the primary affects: Some evidence for a theory. Perception and Motor Skills, 18, 119-156.

Watkins, S. S., Koob, G. F., \& Markou, A. (2000). Neural mechanisms underlying nicotine addiction: Acute positive reinforcement and withdrawal. Nicotine \& Tobacco Research, 2, 19-37.

Watson, D., Clark, L. A., \& Tellegen, A. (1988). Development and validation of brief measures of positive and negative affect: The PANAS scales. Journal of Personality and Social Psychology, 54, 1063-1070.

Watson, D., \& Tellegen, A. (1985). Toward a consensual structure of mood. Psychological Bulletin, 98, 219-235.

West, R. J. (1988). Nicotine: A dependence-producing substance. In O. F. Pomerleau, \& C. S. Pomerleau (Eds.), Nicotine replacement: A critical evaluation (pp. 237-259). New York: Liss.

Wilkerson, J. M., Nagao, D. H., \& Martin, C. L. (2002). Socially desirable responding in computerized questionnaires: When questionnaire purpose matters more than the mode. Journal of Applied Social Psychology, 32, 544-559. 
Copyright of Nicotine \& Tobacco Research is the property of Carfax Publishing Company and its content may not be copied or emailed to multiple sites or posted to a listserv without the copyright holder's express written permission. However, users may print, download, or email articles for individual use. 